\title{
Configurações
}

Revista de sociologia

\section{Narrativa visual e pós-memória: o caso do docudrama Contract, de Guenny Pires}

Visual narrative and post-memory: the case of the Guenny Pires's docudrama Contract

Récit visuel et postmémoire: l'exemple du docudrame Contract de Guenny Pires

Jessica Falconi

\section{OpenEdition}

\section{Journals}

Edição electrónica

URL: http://journals.openedition.org/configuracoes/3289

DOI: 10.4000/configuracoes.3289

ISSN: 2182-7419

\section{Editora}

Centro de Investigação em Ciências Sociais

\section{Edição impressa}

Data de publição: 27 Junho 2016

Paginação: 167-179

ISSN: 1646-5075

\section{Refêrencia eletrónica}

Jessica Falconi, « Narrativa visual e pós-memória: o caso do docudrama Contract, de Guenny Pires », Configurações [Online], 17 | 2016, posto online no dia 30 junho 2016, consultado o 19 abril 2019. URL http://journals.openedition.org/configuracoes/3289; DOI : 10.4000/configuracoes.3289 
Falconi, Jessica - Narrativa visual e pós-memória: o caso do docudrama

Contract, de Guenny Pires. Configurações, vol. 17, 2016, pp. 167-179

\title{
Narrativa visual e pós-memória: o caso do docudrama Contract, de Guenny Pires
}

\author{
JESSICA FALCONI* \\ CeSA-CSG, Universidade de Lisboa
}

\begin{abstract}
Resumo
O docudrama Contract (2010) de Guenny Pires aborda a história dos antigos trabalhadores cabo-verdianos que, durante o colonialismo, foram contratados para as plantações de cacau e café nas ilhas de São Tomé e Príncipe. A narrativa, construída a partir do relato das viagens do realizador à procura do seu tio - o ex-contratado Valdemiro proporciona uma representação significativa da relação entre memória e pós-memória, convocando uma reflexão em torno dos regimes de autoridade instaurados pela escolha da narração em voice-over. O artigo propõe um itinerário de análise destas questões, articulando reflexões teóricas sobre memória e pós-memória aos estudos sobre documentário, tendo em conta também os contextos de produção, circulação e receção do filme como elementos imprescindíveis para uma reflexão situada sobre as suas implicações éticas e estéticas.
\end{abstract}

Palavras-chave: pós-memória, docudrama, Guenny Pires, contratados.

\begin{abstract}
Visual narrative and post-memory: the case of the Guenny Pires's docudrama Contract The docudrama Contract (2010) by Guenny Pires focuses on the history of former Cape Verdean workers who, during colonialism, were hired under a labour contract to work in the cocoa and coffee plantations in São Tomé and Príncipe. The narrative is constructed from the account of the filmmaker's travels in search of his uncle Valdemiro, a former worker in those plantations. The docudrama provides a meaningful representation of the relationship between memory and post-memory, calling for a reflection on the regimes of authority as embodied in by the voice-over narration device. This article proposes an analytical itinerary of such issues and articulates theoretical reflections

\footnotetext{
* Investigadora de Pós-doutoramento no Centro de Estudos sobre Ásia, África e América Latina, Instituto Superior de Economia e Gestão, Universidade de Lisboa. Email: jessica-77@libero.it.
} 
about memory and postmemory with documentary studies. The contexts of production, circulation and receptions of the film are also taken into account as indispensable considerations for addressing the ethical implications and aesthetic dimensions of the film.

Keywords: postmemory, docudrama, Guenny Pires, contratado.

\section{Résumé}

Récit visuel et postmémoire : l'exemple du docudrame Contract de Guenny Pires

Le docudrame Contract (2010) de Guenny Pires raconte l'histoire des anciens travailleurs du Cap-Vert qui, pendant le colonialisme, ont été embauchés dans les plantations de cacao et de café dans les îles de Sao Tomé-et-Principe. L'histoire, construite à partir du récit des voyages du réalisateur quand il recherchait son oncle Valdemiro, fournit une représentation significative de la relation entre mémoire et postmémoire, appelant à une réflexion sur les régimes d'autorité instaurés par le choix de la narration en voix off. L'article propose un itinéraire analytique de ces questions, articulant des réflexions théoriques sur la mémoire et la postmémoire avec les études sur le documentaire, en tenant compte des contextes de production, de circulation et la réception du film comme éléments essentiels pour une réflexion située sur ses implications éthiques et esthétiques.

Mots-clés: postmémoire, docudrame, Guenny Pires, contratado.

O docudrama Contract de Guenny Pires, sobre os ex-trabalhadores cabo-verdianos contratados durante o colonialismo para as roças de São Tomé e Príncipe, levanta um conjunto de questões significativas sobre as relações entre história, memória e pós-memória, bem como sobre a representação da identidade cultural no domínio do audiovisual. O tópico do filme - o sistema da mão-de-obra contratada para as roças do arquipélago equatorial - constitui um capítulo complexo e ainda pouco conhecido da história do colonialismo português em África. Trata-se de um legado do Império com o qual as sociedades e os Estados africanos independentes lidam com grande dificuldade, mantendo os antigos contratados, e por vezes seus descendentes, em condições de profunda marginalização socioeconómica. Se por um lado o filme realça a urgência de se encontrarem soluções políticas e pragmáticas para a condição destes sujeitos, por outro lado ele assinala também a importância da memória desta página do passado colonial para a presente e progressiva construção das sociedades pós-coloniais. De facto, Contract não é o único filme que surgiu sobre este tópico: outros realizadores cabo-verdianos, nomeadamente Leão Lopes e Júlio Silvão Tavares, realizaram, respetivamente, São Tomé e Príncipe. Os últimos contratados (2010) e São Tomé. Minha terra, minha mãe \& minha madrasta $(2012)^{1}$. Como assinala o título do filme de Leão Lopes, os 
últimos contratados - que emigraram de Cabo Verde para São Tomé em finais da década de 1940, na sequência do impacto da Segunda Guerra Mundial e da grande fome do biénio 1947-49 - começam a desaparecer, tornando assim mais premente a releitura desta página da história através de seus testemunhos.

Por outro lado, se pensarmos que em 2015 Cabo Verde e as outras ex-colónias portuguesas em África comemoraram os 40 anos da independência, podemos enquadrar tal necessidade de memória numa mais vasta dimensão de releitura do passado antigo e recente das novas nações e sociedades. Se por um lado a literatura produzida por escritores oriundos destes países tem sido pioneira neste aspeto, privilegiando frequentemente a relação entre história e memória, verifica-se esta tendência também noutros domínios de produção cultural. Em países como Angola e Moçambique, as experiências traumáticas da guerra de libertação e dos conflitos pós-independência ocupam hoje um lugar central nas produções de memória constituídas por um conjunto diversificado de publicações - livros de memórias, biografias, autobiografias, etc. Em São Tomé e Príncipe, assiste-se a um fenómeno análogo relativamente à memória dos contrastes violentos entre a administração colonial portuguesa e a população local - eventos ocorridos em 1953 e que ficaram conhecidos pelo nome de Massacre de Batepá. Também no domínio específico da historiografia, assiste-se a uma reflexão cada vez mais significativa sobre a relação entre história e memória, patente em projetos académicos e culturais que articulam os paradigmas da Nova História, da História Oral, dos Estudos Subalternos e Pós-coloniais, visando incorporar as memórias e as narrativas pessoais sobre momentos ou figuras fundacionais da nação no intuito de pluralizar a narrativa da nação, muitas vezes hegemonizada pelo discurso político ou por paradigmas epistemológicos de cunho colonial e eurocêntrico. Trata-se de exemplos diversos, cuja análise não cabe no propósito deste texto, mas que dão conta tanto da necessidade destas sociedades se confrontarem com o seu passado problemático, quanto do papel da memória enquanto instrumento de poder (Le Goff, 1986) que, tal como a história, gera conflitos entre grupos e interesses distintos na produção de diferentes "políticas de memória" (Huyssen, 2003).

Neste quadro geral brevemente esboçado, o filme de Guenny Pires ${ }^{2}$ apresenta um conjunto de caraterísticas que o tornam especialmente significativo para refletirmos sobre as estratégias de representação que convocam a história, a memória e a pós-memória, bem como a identidade cultural e a diáspora. De facto, se por um lado a escolha do tópico do contrato insere-se neste movimento mais generalizado de regresso a um passado por vezes silenciado

2 Guenny Pires nasceu em 1965 em Mira-Mira, uma pequena aldeia na Ilha do Fogo, Cabo Verde. Durante a infância e a adolescência viveu também na cidade da Praia, na ilha de Santiago, e em São Vicente. Mudou-se para Portugal para prosseguir os estudos na área da sociologia e do cinema, e mais tarde para os Estados Unidos, onde se especializou na prática e no ensino do cinema. Atualmente reside em Los Angeles, onde fundou, juntamente com outros membros, a Txan Film Productions \& Visual Art. 
de Cabo Verde, via São Tomé e Príncipe, por outro lado, no caso do filme Contract, a História nacional entrelaça-se com a história pessoal e familiar do realizador, sendo o docudrama um percurso pessoal em busca de laços parentais perdidos. Nesta perspetiva, o filme partilha de alguns traços caraterísticos do que vem sendo definido de trabalho da pós-memória, sendo a emigração dos cabo-verdianos para as ilhas de São Tomé e Príncipe - induzida pelas condições precárias e pelos interesses do poder colonial - o trauma histórico (Pollock, 2009) que marcou a família do realizador. De facto, o contato com o sofrimento causado pela separação experienciada pela sua família é o fator que desencadeia o motor da narração encenada em Contract: viajar à procura e ao encontro do tio Valdemiro, irmão da sua mãe, Marina. Por um lado, o objetivo do filme é favorecer o reencontro entre Marina e Valdemiro, cuja relação residiu durante muito tempo apenas em trocas de cartas. Por outro lado, o realizador pretende "adotar" as experiências traumáticas familiares o sofrimento pela separação - e inscrevê-las na sua própria história pessoal e artística: "As a filmmaker, this docudrama is very personal and touch me as an artist", afirma o realizador no principio do filme, continuando: "My experience with the sadness of the separation of so many of my people motivated me to be an active participant on this production". Esta "adoção" das memórias dos outros, bem como o investimento criativo e imaginativo nelas por parte de quem não as experienciou em primeira pessoa, são alguns dos traços que caraterizam o trabalho da pós-memória. De acordo com Marianne Hirsch, "Postmemory's connection to the past is thus not actually mediated by recall but by imaginative investment, projection, and creation" (Hirsch, 2008: 107). Um exemplo que dá conta deste investimento criativo, bem como da intenção de "adotar" as memórias dos outros é dado logo no início do filme. Antes de introduzir a história de Marina e Valdemiro - mãe e tio do realizador - o intertítulo "Separation" é logo seguido de uma cena filmada entre um grupo de pessoas de origem cabo-verdiana em São Tomé. "Bom caminho", "Vai com Deus" são as frases de despedida pronunciadas por uma mulher, olhando fixo para a câmara, dirigidas provavelmente ao realizador. Cria-se assim no espetador uma associação imediata entre o tópico da separação e o fim das filmagens naquele lugar, remetendo para a inscrição da separação na história pessoal e no percurso artístico do realizador.

A dimensão traumática experienciada por Marina é sublinhada no filme através da incapacidade dela em articular o seu sofrimento numa narrativa. Antes do reencontro com o irmão, perante a câmara Marina seca as lágrimas, mostra cartas e envelopes, e quando o realizador lhe pergunta "Mãe, conta a história do teu irmão que foi para São Tomé”, ela apenas responde que o irmão foi para São Tomé há muitos anos sem nunca ter regressado, e que ela gostaria de o rever antes de morrer. Enquanto Marina pronuncia estas frases, vemos no ecrã imagens a preto e branco de um grupo de pessoas num barco, 
e de Valdemiro enquanto caminha entre as árvores. Como é evidente, trata-se de uma encenação do evento que originou o trauma da separação. De facto, de acordo com Guenny Pires, Contract é uma docudrama, um subgénero do documentário em que partes da narrativa são "encenadas", combinando ficção e realidade, bem como pretensões de referencialidade e um elevado poder imaginativo (Corner, 1996). Em Contract as sequências encenadas são projetadas como se pertencessem a um filme antigo. Tal artifício coloca-nos perante o jogo complexo dos mecanismos da memória e da pós-memória no domínio do audiovisual. Como foi referido, o trauma histórico em que se insere a história da separação entre Marina e Valdemiro é o mais amplo fenómeno da emigração da mão-de-obra contratada durante a época colonial. É este o evento cuja memória, "herdada" pelo sujeito da pós-memória, só pode ser recriada através do contato íntimo com o sofrimento de quem o experienciou, e de um investimento da imaginação: perante a dificuldade de Marina em narrar o trauma, o realizador atribui-lhe memórias que, na realidade, são as memórias mediadas que ele próprio cria e encena no filme para que o trauma se transforme em representação e narração. Além disso, o jogo da representação complica-se pelo facto de as pós-memórias do realizador projetadas no filme serem literalmente encenadas pela testemunha do evento: o tio Valdemiro. Estas imagens são desenvolvidas em diversos momentos do filme. De facto, logo a seguir à cena do primeiro encontro entre o realizador e o tio, em São Tomé, marcado pela emoção e as lágrimas de Valdemiro, a voz narradora conta a história da partida do tio de Cabo Verde aquando do início do contrato, em 1964. No ecrã, vemos a preto e branco a despedida entre Valdemiro de mala na mão e os familiares, a subida a um barco e a chegada a São Tomé. Também depois de o realizador ter conseguido organizar o reencontro entre Marina e Valdemiro, já todos reunidos em Cabo Verde, esta complexa interação entre memória e pós-memória é assinalada através de uma sequência em que vemos o retrato do próprio realizador quando criança e logo a seguir um roteiro de Valdemiro pelos lugares do seu passado. Trata-se de um momento de grande intensidade narrativa, já que a criança do retrato, em primeiro plano, olha fixamente para a câmara, enquanto ouvimos o realizador afirmar: "When my uncle left his birthplace I have not been born yet. He is taking me back to show me his roots and memories". Finalmente, o próprio Valdemiro toma a palavra para responder às perguntas do realizador sobre o dia da partida, e o mesmo artifício visual das encenações a preto e branco sublinha o modo como o realizador retrabalha as memórias familiares que se inscreveram no seu próprio percurso. Assim, a narrativa visual mostra a lacuna entre o retrato da criança que olha para a câmara e as imagens encenadas da partida do tio: a distância entre quem não esteve lá e não vivenciou a separação e o evento relembrado pela testemunha preenche-se através da proximidade afetiva e do trabalho imaginativo da pós-memória. Por outro lado, o recurso ao artifício visual das memórias encenadas, que recorre 
em três momentos distintos do filme, pode também assinalar a tarefa assumida pelo sujeito da narração em seu esforço de criar um espaço intersubjetivo de memória partilhada entre o realizador, a mãe e o tio, no intuito de preencher o vazio criado pela dispersão e pela separação familiar.

O filme torna-se assim uma viagem empreendida para se tentar compreender as lacunas de uma história simultaneamente pessoal e coletiva, buscando articular, a partir do vazio criado pela distância, uma narrativa sobre a separação e a emigração, que, neste caso específico, remete para a mais ampla questão da diáspora cabo-verdiana. Contudo, ainda de acordo com as afirmações iniciais do realizador, o filme é também "a journey to bring awareness, knowledge and consciousness to Africa's smallest country of São Tomé and Príncipe”. Assim, desde o princípio do filme, o espetador encontra-se perante uma viagem de múltiplos itinerários que cruzam as fronteiras entre história, memória e pós-memória; entre o individual e o coletivo, bem como entre a intenção documental e a experimentação estética.

A opção de Guenny Pires pelo docudrama remete, possivelmente, para esta multiplicidade de propósitos, convocando à partida um conjunto de questões significativas que dizem respeito à dimensão mediada e ficcional do acesso ao passado histórico, por parte de quem não viveu os eventos; à representação deste passado, e sobretudo aos complexos regimes de autoridade que estão em jogo em qualquer projeto de releitura do passado em geral, e no docudrama em particular.

A relação privilegiada entre filme documentário e História é, por vezes, uma relação óbvia que, como esclarece Paula Rabinowitz, investe múltiplos níveis: a própria história do documentário; o uso da história no documentário, ou ainda o uso do documentário por parte dos historiadores (Rabinowitz, 1993). Desde as suas primeiras manifestações, o filme documentário tem sido uma das formas institucionalizadas mais eficazes de transmissão do passado histórico de uma coletividade, constituindo um instrumento poderoso para a criação de versões partilhadas da história e para a configuração da memória cultural, que é hoje cada vez mais moldada pela interação entre distintos meios de comunicação (Erll, 2008). Por outro lado, se a massificação do consumo de documentários históricos - veja-se o sucesso de canais de televisão como History Channel - tem vindo a alimentar o fenómeno de mercadorização e espetacularização da memória (Huyssen, 2003), é verdade também que a pluralização do seu uso por parte dos realizadores tornou-o num género de grande versatilidade e criatividade, utilizado para veicular releituras e visões íntimas do passado. Como realça John Corner, o documentário como "interrogação radical e perspetiva alternativa", surgido inicialmente no domínio do cinema independente, é uma das funções principais que distinguem um número significativo de produções (Corner, 2002: 259-260). Esta função em particular adquire ainda mais relevância em contextos pós-coloniais tais como Cabo 
Verde e outros países africanos, onde a produção de documentários é mais um elemento que se enquadra na exigência de reinterpretar o passado e pluralizar as narrativas nacionais monolíticas veiculadas pelo discurso político.

Mas qual a relação entre documentário propriamente dito e docudrama ${ }^{3}$ ? Por um lado, a natureza cada vez mais multifacetada do documentário tem vindo a originar extensos debates sobre a definição do género, cuja identidade, para Corner, está hoje numa fase de profunda instabilidade, ao ponto de se colocar a hipótese de estarmos a transitar para uma cultura "pós-documentária”. Por outro lado, tal como ocorreu no domínio da historiografia, também nos estudos sobre documentário, muitos estudiosos têm vindo a analisar a relevância das estruturas narrativas no tratamento da realidade e da história na produção deste tipo de filmes. Relativamente ao docudrama, a sua natureza híbrida tem levantado também inúmeros debates, cujo traço distintivo diz respeito a uma certa desvalorização baseada sobretudo no facto de o docudrama se ter configurado como um género de amplo consumo também pela sua ligação aos circuitos de televisão (Fournier, 2013). Por outro lado, como observa Steven Lipkin, boa parte dos estudos produzidos na área da teoria do documentário tende a focar a dimensão documental do docudrama, preocupando-se principalmente com o modo como o facto histórico sai deformado ou afetado pela representação docudramática, afetando o regime de credibilidade e legitimidade da versão da realidade proposta (Lipkin, 2002).

Se aparentemente se trata de um género recente, na realidade as suas caraterísticas principais fazem parte da inteira história do cinema (Rosenthal, 1999). No docudrama estado-unidense tradicional - como o próprio termo docudrama sugere - os eventos “reais” são recriados através dos códigos narrativos do melodrama próprios da indústria cinematográfica de Hollywood. Em muitas destas produções, atores profissionais interpretam papéis de personagens reais, e geralmente conhecidas junto do grande público, tal como o são os eventos recriados. Esta é uma das razões que ajuda a explicar também a ampla difusão do docudrama e do seu consumo nos circuitos de televisão.

Frente às caraterísticas gerais, o docudrama de Guenny Pires apresenta diferenças significativas. Em primeiro lugar, o tema abordado em Contract diz respeito a realidades históricas e a comunidades ainda pouco conhecidas e pouco representadas junto de um público internacional. Esta circunstância é salientada pelo realizador através de uma ampla exploração da dimensão informativa e divulgativa do filme, que de facto apresenta um conjunto de

3 Apesar de o debate terminológico estar ainda em aberto, o termo docudrama surge da contração do sintagma documentary drama, e é utilizado, principalmente mas não exclusivamente, para se referir a produções oriundas dos Estados Unidos. Noutros contextos anglo-saxónicos formas híbridas de representação são designadas pelos termos drama documentary ou dramadoc. Partindo das nuances terminológicas, diversos estudos têm explorado os elementos suscetíveis de marcar diferenças entre estes termos, ou seja, as formas como os dois elementos - documentário e drama - são explorados para produzir efeitos distintos. Para estes debates, ver, entre outros, Paget (1998) e Rosenthal (1999). 
dados geográficos, históricos, económicos e sociológicos sobre os arquipélagos de São Tomé e Príncipe e de Cabo Verde, possivelmente dirigidos tanto para quem pertence a estas comunidades como para o público em geral. Por um lado, esta dimensão é obviamente funcional à construção da credibilidade do realizador perante o público em relação à matéria tratada, reforçada pelo recurso a entrevistas e depoimentos de estudiosos, especialistas e personalidades de renome internacional, como é o caso de Noam Chomsky. Por outro lado, esta dimensão insere-se também no percurso pessoal de conhecimento do passado familiar, funcionando como propedêutica ao reencontro com o tio. Nesta perspetiva, como salienta Lipkin, o docudrama não se limita apenas a combinar elementos documentais e recursos dramáticos, já que eles interagem e se entrelaçam para produzir uma determinada visão de conjunto do tópico tratado (Lipkin, 2002).

No que se refere à questão das personagens, em Contract estamos perante o caso de indivíduos reais que se interpretam a si mesmos - o realizador, Marina, Valdemiro e outros familiares. Sobre este aspeto, as observações de Stella Bruzzi a propósito dos diferentes usos da performance no docudrama e em outras produções não-ficcionais são particularmente esclarecedoras. Para Bruzzi, no docudrama, "a masquerade of spontaneity can be seen to function at an overt level", sendo o papel da performance paradoxal na medida em que permite tornar mais "real” e mais veraz a ficcionalização (Bruzzi, 2000:153). Pelo contrário, no documentário propriamente dito, o uso da performance chama a atenção para todos aqueles elementos ou eventos cuja representação documentária autêntica é praticamente impossível. Porém, contrariamente ao que Bruzzi afirma em relação ao uso da performance no docudrama - cujo efeito seria tornar mais autêntica a ficcionalização - em Contract a performance parece-nos funcionar de forma distinta. Mais do que garantir autenticidade e veracidade à representação, a performance realça a natureza ficcional e mediada da memória e da pós-memória, revelando assim as potencialidades do docudrama para a abordagem do passado (Lipkin, 2011).

Também o papel do realizador em relação ao mundo filmado é um aspeto crucial para refletirmos sobre a relação entre as diversas instâncias de memória e conhecimento presentes no docudrama de Guenny Pires. Como é sabido, as caraterísticas que marcam a relação entre o realizador e os sujeitos filmados têm tido um papel fundamental na abordagem e classificação de diferentes estilos, modos ou tipologias de documentários (Nichols, 2001). Em Contract, em primeiro lugar, mesmo quando não vemos o corpo do realizador perante a câmara, ouvimos a sua voz durante quase todo o filme, graças ao recurso à narração em voice-over. Trata-se de um recurso que o docudrama partilha largamente do documentário (Paget, 1998). Em muitos documentários, tem sido atribuída uma função informativa e didática a este recurso, integrado no aparato de contextualização histórica e de crítica social explícita, veiculado 
através de legendas, entrevistas, depoimentos, imagens de arquivo, etc. Bill Nichols associa este recurso, principalmente, ao documentário do estilo expositivo, onde a voz - muitas vezes masculina e num tom aparentemente impessoal - cumpre um papel autoritário de organização das imagens, orientando a interpretação ao colocar o ênfase em determinados significados entre os muitos que poderiam surgir da visão. Em muitos filmes documentários, a narração em voice-over pretende garantir uma verdade, e afirmar desde o princípio a objetividade do tratamento da matéria. Por outro lado, como realça Bruzzi, ao dirigir-se de modo direto ao espetador, a narração em voice-over é suscetível de introduzir também instâncias de intimidade ou ironia, capazes de alterar e transgredir o papel de objetividade tradicionalmente associado a este tipo de recurso (Bruzzi, 2000). Utilizada muitas vezes de forma extradiegética, a narração em voice-over adquire outros significados quando a voz pertence ao realizador, e quando o próprio realizador não apenas aparece perante a câmara, mas pertence ao mundo filmado e atua enquanto personagem, como no caso de Contract. Assim, o docudrama investe numa articulação complexa de recursos e códigos que afeta os regimes de autoridade que regulam os projetos de releitura do passado. Novamente, a natureza performativa do docudrama aponta para a dimensão subjetiva e íntima associada ao conhecimento do passado. De facto, por um lado, em Contract o realizador procura conhecer a história e a realidade do passado recorrendo ao conjunto de elementos disponibilizados pela memória pública, tais como imagens, documentos, depoimentos de historiadores, etc. Por outro lado, a presença da voz e do corpo do realizador nos lugares onde se processou o trauma histórico vivenciado pela família, bem como as recriações do passado protagonizadas por Valdemiro, remete para o desejo do sujeito da pós-memória de testemunhar o evento, o que apenas se pode realizar no domínio da performance, permitindo também balançar as instâncias de autoridade em jogo no conhecimento e na memória do passado. O arquivo, o corpo, a voz; a história, a memória e a pós-memória: Contract convoca e operacionaliza instâncias de autoridade distintas e em competição entre elas, que devolvem uma experiência audiovisual que poderíamos definir epistemologicamente polifónica - do ponto de vista do áudio - e multifacetada - do ponto de vista do visual.

Estes múltiplos itinerários de reflexão refletem-se também na construção narrativa da viagem do realizador ao encontro do tio: de Los Angeles a Boston, onde reside a mãe, e daqui a Cabo Verde, ao encontro de uma tia, Maria Candeia, para, de acordo com as palavras de Guenny Pires: "learn more about the life of my family, back in the Sixtie's". Em todos estes lugares, tanto a imagem material quanto a ideia da "casa" são evocadas com frequência. Entre as primeiras cenas do filme, um plano geral retrai o exterior de um edifício em Boston, e logo a seguir o interior da casa onde vive Marina. Em São Tomé, Valdemiro conta que a casa e a plantação onde vivia foram destruídas por um 
incêndio. Também em Cabo Verde, o realizador e o tio visitam os locais onde surgia a antiga casa de Valdemiro, num terreno que pertencia à mãe dele. Por outro lado, as frequentes imagens dos aeroportos e dos aviões que conectam os Estados Unidos e os dois arquipélagos complementam a paisagem física e simbólica desenhada no docudrama, enriquecida também por uma banda sonora fortemente protagonizada por músicas cabo-verdianas sobre a emigração para São Tomé, assumindo a música um papel central no dimensionamento simbólico e cultural da memória e da pós-memória. A ideia de “casa” surge assim associada quer ao sentimento da perda e ao momento da partida, quer à força da memória e ao ato do regresso. As imagens e os relatos relacionados com as casas projetam uma triangulação geográfica e afetiva entre Cabo Verde, São Tomé e Estados Unidos que não pertence apenas à dimensão privada do realizador. De facto, esta triangulação é também uma paisagem cultural e identitária coletiva, sendo os Estados Unidos - país de residência do realizador - outro polo central da diáspora cabo-verdiana. Esta paisagem molda, e é simultaneamente moldada, pelo tratamento do tópico do contrato por parte do realizador. De facto, a parte de pendor mais informativo e crítico do docudrama, introduzida pelo intertítulo "Slavery and Democracy", investe, através de múltiplos recursos, em conectar a história da mão-de-obra contratada nas antigas colónias portuguesas à mais ampla história da escravatura que envolveu também o Novo Mundo. Do ponto de vista histórico, as ligações entre estes dois fenómenos são evidentes, na medida em que, de acordo com diversos historiadores, nas colónias portuguesas em África, o sistema do contrato surgiu também para se contornar o problema do trabalho agrícola após a abolição formal da escravatura, prolongando-se, no que se refere à emigração cabo-verdiana para São Tomé, até à década de 1970 (Carreira, 1983). Por outro lado, a questão das condições de degradação humana e social em que viviam os contratados nas roças e as circunstâncias que muitas vezes impediam o regresso para a terra de origem são outros aspetos que têm levantado reflexões diversas sobre as semelhanças e diferenças entre o sistema da escravatura, o do trabalho forçado e o do trabalho contratado (Nascimento, 2007; Zamparoni, 2004). O docudrama Contract traz para o ecrã estas questões tanto no plano da história - através, por exemplo, das entrevistas a estudiosos - quanto no plano da memória, graças aos depoimentos de antigos contratados sobre as suas condições de trabalho durante o tempo colonial. A inserção no filme de diversas imagens de ampla difusão - desenhos, gravuras, fotografias - suscetíveis de evocar a iconografia da escravatura aponta também para um investimento no plano imagético-simbólico que reforça a triangulação criada pela história pessoal e familiar do realizador, sugerindo uma ressignificação desta paisagem. Por outras palavras, ao conectar a história familiar e da comunidade cabo-verdiana, marcadas pelo contrato, ao tema e aos símbolos da escravatura, o docudrama parece apontar para um diálogo e uma articulação de memórias e pós-memórias distintas e 
distantes que encontram um possível ponto de contato nas ideias do panafricanismo. Com palavras de Marianne Hirsch,

Postmemorial work, I want to suggest [...] strives to reactivate and reembody more distant social/national and archival/cultural memorial structures by reinvesting them with resonant individual and familial forms of mediation and aesthetic expression. Thus less-directly affected participants can become engaged in the generation of postmemory, which can thus persist even after all participants and even their familial descendants are gone. (Hirsch, 2008:111)

Por outro lado, uma chave importante para a abordagem da triangulação entre Estados Unidos, Cabo Verde e São Tomé criada por Contract, diz respeito também ao circuito de produção, circulação e receção do filme. O contexto da produção adquire um papel relevante no próprio corpo da diegese. Guenny Pires mostra e descreve os seus equipamentos, contando que em São Tomé teve de pedir ajuda a amigos para encontrar outro material técnico para as filmagens. Alude às ajudas financeiras que recebeu para conseguir reunir o tio e a mãe em Cabo Verde e, sobretudo, alude às despesas que teve de enfrentar - equipamentos, bilhetes de avião, etc. A este propósito, em São Tomé, a câmara foca durante vários segundos as notas que pagou a um taxista. Também a dimensão da receção é evocada dentro da narrativa, quando o realizador regressa a Boston e mostra à mãe as imagens do tio Valdemiro, gravadas num dispositivo móvel. Todos estes elementos salientam, como é evidente, a dimensão material - logística, económica, tecnológica - que, trazida para dentro da narrativa, é de certo modo inseparável dela, reforçando, mais uma vez, a dimensão mediada, material e tecnológica que informa o trabalho da memória e da pós-memória. A opção pelo docudrama aponta também para o circuito material e a tradição fílmica em que Contract se insere, tratando-se, como foi referido, de um modo de representação especialmente difuso e cultivado nos Estados Unidos, e é significativo que, no filme, vemos o celebérrimo letreiro de "Hollywood" quer no princípio, numa vista do Mount Lee, quer depois, já em Cabo Verde, estampado numa t-shirt usada por Valdemiro - talvez uma prenda do sobrinho, que reforça as conexões até aqui referidas.

Contract insere-se nos projetos da Txan Film Productions \& Visual Arts, fundada em Los Angeles por Guenny Pires e outros membros. De acordo com a apresentação da produtora,

Its aim is to produce informative multi-media resources and entertainment that cover societies and cultures within the African Diaspora - primarily of the Atlantic region (islands of the Caribbean, Cape Verde, São Tomé and Príncipe) and the Americas, that is not normally covered by mainstream media and/or within scholarly discourse. (www.txanfilm.com) 
O filme foi exibido em diversos lugares, tendo sido premiado no Roxbury International Film Festival (Award for best documentary, 2010), no Festival Internacional de Cabo Verde (Award for best feature film, 2013) e no Cape Verdean American Film Festival (Award for best film, 2014).

As indicações da produtora, bem como a receção do filme nos festivais, iluminam outro aspeto de Contract, que remete para o posicionamento constantemente in-between do realizador, em relação ao contexto de produção e receção, bem como em relação aos sujeitos da representação. Ao utilizar um modo de representação mainstream no mercado estado-unidense, com o objetivo de veicular histórias e memórias percecionadas como "outras" neste mesmo mercado, o realizador transita na triangulação Estados Unidos-Cabo Verde-São Tomé tanto como insider quanto como outsider, o que remete para o conceito de identidade cultural formulado por Stuart Hall. É, de facto, a partir do cinema e das representações visuais que Stuart Hall desenvolveu o seu pensamento sobre a identidade cultural. Retomando Frantz Fanon, Hall interroga a natureza da investigação no passado realizada pelas representações cinematográficas:

Is it only a matter of unearthing that which the colonial experience buried and overlaid, bringing to light the hidden continuities it suppressed? Or is a quite different practice entailed - not the rediscovery but the production of identity. Not an identity grounded in the archeology, but in the re-telling of the past? (Hall, 1990: 224)

Para Hall, as identidades culturais são pontos instáveis de identificação dentro dos discursos da história e da cultura, sendo menos essências do que posicionamentos: "Identities are the names we give to the different ways we are positioned by, and position ourselves within the narratives of the past" (225). Como é evidente, este conceito da identidade cultural enquanto posicionamento dialoga com a noção de trabalho da pós-memória teorizado por Hirsch. Em ambos os casos, o relacionamento com o passado dá-se através de um trabalho criativo - e doloroso - de ressignificação de narrativas dos outros que dominam o presente e, dentro das quais, é preciso procurar, mais do que encontrar, um possível posicionamento, um ponto de identificação constantemente instável. O trabalho da pós-memória parece-nos suscetível de traduzir outra declinação do ser in-between, sendo o sujeito da pós-memória simultaneamente insider e outsider em relação aos eventos traumáticos que não vivenciou mas que o dominam a nível identitário. Como tentei demonstrar, o trabalho da pós-memória desenvolvido pelo docudrama de Guenny Pires articula-se à representação da identidade cultural cabo-verdiana, ao convocar a memória da emigração para São Tomé enquanto componente traumática, e muitas vezes recalcada, desta mesma identidade, tanto a nível coletivo, quanto individual. 
Por outro lado, a articulação operada no docudrama entre a história familiar e nacional do realizador, e a história da escravatura, cria pontes e ressonâncias que projetam quer o circuito material de produção, circulação e receção, quer um espaço simbólico transnacional de identificação cultural.

Procurei também demonstrar que a escolha do subgénero do docudrama e a utilização da narração em voice-over são recursos de grande alcance para a representação da memória e da pós-memória, na medida em que convocam regimes de autoridade distintos e instáveis, apontando para a complexidade da apreensão e da releitura do passado. Trata-se de um passado produzido pelas "malhas que o império teceu", e reconfigurado pelas narrativas da memória e da pós-memória no tempo pós-colonial (Mezzadra, 2008).

\section{Referências}

BRUZZI, Stella (2000), New Documentary: a Critical Introduction. London \& New York: Routledge. CARREIRA, António (1983), Migração nas Ilhas de Cabo Verde. Lisboa: Instituto Cabo-verdiano do Livro.

CORNER, John (1996), The Art of Record: a Critical Introduction. Manchester: Manchester University Press.

CORNER, John (2002), "Performing the Real: Documentary Diversions". Television \& New Media, 3: 255-269.

ERLL, Astrid (2008), “Literature, Film, and the Mediality of Cultural Memory”, in Astrid Erll and Ansgar Nünning (ed.) Media and Cultural Memory. Berlin, Walter de Gruyter, 389-398.

FOURNIER, Georges (2013), "British Docudrama”. InMedia, 3: 2-16.

HALL, Stuart (1990), "Cultural Identity and Diaspora”, in Jonathan Rutherford (ed.) Identity: community, culture, difference. London: Lawrence \& Wishart, 222-237.

HIRSCH, Marianne (2008), “The Generation of Postmemory”. Poetics Today, 29 (1): 103-128.

HUYSSEN, Andreas (2003), Present Pasts: Urban Palimpsests and the Politcs of Memory. Stanford: Stanford University Press.

LE GOFF, Jacques (1986), Storia e memoria. Torino: Einaudi.

LIPKIN, Steven (2011), Docudrama Performs the Past: Arenas of Arguments in Films based on True Stories. Newcastle: Cambridge Scholar Publishing.

LIPKIN, Steven (2002), Real emotional logic. Carbondale and Edwardsville: Southern Illinois University Press.

MEZZADRA, Sandro (2008), La condizione postcoloniale. Verona: Ombre Corte.

NASCIMENTO, Augusto (2007), O Fim do Caminhu Longi. Praia: Ilhéu Editora.

NICHOLS, Bill (2001), Introduction to Documentary. Bloomington and Indianapolis: Indiana University Press.

PAGET, Derek (1998), No Other Way to Tell it: Dramadoc/Docudrama on Television. Manchester: Manchester University Press.

POLLOCK, Griselda (2009), “Art/Trauma/Representation”. Parallax, 15 (1): 40-54.

RABINOWITZ, Paula (1993), "Wreckage upon Wreckage: History, Documentary and the Ruins of Memory". History and Theory, 32 (2): 119-137.

ROSENTHAL, Alan (1999), Why Docudrama?: Fact-fiction on Film and TV. Carbondale: Southern Illinois University Press.

ZAMPARONI, Valdemir (2004), "Da escravatura ao trabalho forçado: teorias e práticas". Africana Studia, 7: 299-325. 


\section{Filmografia citada}

Leão Lopes (2010) São Tomé e Príncipe. Os últimos contratados. Leão Lopes.

Guenny Pires (2010) Contract. Txan Film Productions \& Vision Art.

Júlio Silvão Tavares (2012) São Tomé. Minha terra, minha mãe \&o minha madrasta. Silvão-Produção.

Submetido: 28-02-2016

Aceite: 15-06-2016 